\title{
Hyperexcitability of Distal Dendrites in Hippocampal Pyramidal Cells after Chronic Partial Deafferentation
}

\author{
Xiang Cai, ${ }^{1 \star}$ Dong-Sheng Wei, ${ }^{2 \star}$ Sandra E. Gallagher, ${ }^{1,3}$ Ashish Bagal, ${ }^{1,4}$ Yan-Ai Mei, ${ }^{5}$ Joseph P. Y. Kao, ${ }^{1,6}$ \\ Scott M. Thompson, ${ }^{1}$ and Cha-Min Tang ${ }^{1,2,7}$ \\ Departments of ${ }^{1}$ Physiology, ${ }^{2}$ Neurology, and ${ }^{3}$ Medical and Research Technology and ${ }^{4} \mathrm{MD} / \mathrm{PhD}$ Training Program, University of Maryland School of \\ Medicine, Baltimore, Maryland 21201, 5 Department of Physiology and Biophysics, School of Life Sciences, Fudan University, Shanghai 200433, China, \\ ${ }^{6}$ Medical Biotechnology Center, University of Maryland Biotechnology Institute, Baltimore, Maryland 21201, and ${ }^{7}$ Neurology Service, Baltimore Veterans \\ Affairs Medical Center, Baltimore, Maryland 21201
}

Traumatic injury to the CNS results in chronic partial deafferentation of subsets of surviving neurons. Such injuries are often followed by a delayed but long-lasting period of aberrant hyperexcitability. The cellular mechanisms underlying this delayed hyperexcitability are poorly understood. We developed an in vitro model of deafferentation and reactive hyperexcitability using organotypic hippocampal slice cultures to study the underlying cellular mechanisms. One week after transection of the Schaffer collateral and temporoammonic afferents to CA1 neurons, brief tetanic stimulation of the residual excitatory synapses produced abnormally prolonged depolarizations, compared with responses in normally innervated neurons. Responses to weak stimulation, in contrast, were unaffected after deafferentation. Direct stimulation of distal apical dendrites using focal photolysis of caged glutamate triggered abnormally prolonged plateau potentials in the deafferented neurons when strong stimulation was given, but responses to weak stimulation were not different from controls. An identical phenotype was produced by chronic "chemical deafferentation" with glutamate receptor antagonists. Responses to strong synaptic and photolytic stimulation were selectively prolonged by small-conductance (SK-type) calcium-activated potassium channel blockers in normally innervated cells but not after deafferentation. No significant changes in SK2 mRNA or protein levels, GABAergic inhibition, glutamate receptor function, input resistance, or action potential parameters were observed after chronic deafferentation. We suggest that a posttranslational downregulation of SK channel function in thin distal dendrites is a significant contributor to deafferentation-induced reactive hyperexcitability.

Key words: epilepsy; glutamate; potassium channels; injury; synaptic plasticity; deafferentation

\section{Introduction}

A remarkable characteristic of the CNS is its capacity to change its behavior in response to differing inputs and experiences (Turrigiano, 1999). An important but incompletely understood aspect of neural plasticity is the response of the CNS to injury. Injury to the brain frequently results in aberrant excitability, including posttraumatic epilepsy, central pain syndrome, and spasticity. Interestingly, the hyperexcitability only becomes apparent with a delay after injury, at about the same time as the first evidence of recovery. Aberrant reactive hyperexcitability may therefore share some of the same mechanisms that are recruited for CNS repair and homeostasis. A better understanding of reactive hyperexcitability should provide insights into the management of hyperex-

Received Jan. 25, 2006; revised Nov. 10, 2006; accepted Nov. 12, 2006.

This work was supported by the National Institute of Neurological Disorders and Stroke (S.M.T., C.-M.T.), National Institute of Mental Health (S.M.T.), National Institute of General Medical Sciences (J.P.Y.K.), and Veterans Health Administration (C.-M.T.). We thank Dr. J. Adelman (Vollum Institute, Portland, OR) for providing the anti-SK2 antibody and SK2 knock-out mice, Dr. B. Alger for comments on this manuscript, and Dr. S. Muralidharan for synthesis of caged glutamate.

*X.C. and D.-S.W. contributed equally to this work.

Correspondence should be addressed to Scott Thompson, Department of Physiology, University of Maryland School of Medicine, 655 West Baltimore Street, Baltimore, MD 21201. E-mail: sthom003@umaryland.edu.

DOI:10.1523/JNEUROSCI.4502-06.2007

Copyright $\odot 2007$ Society for Neuroscience $\quad 0270-6474 / 07 / 270059-10 \$ 15.00 / 0$ citable neurological disorders, as well as fundamental mechanisms of CNS homeostasis.

One elemental aspect of brain injury is the chronic partial deafferentation of surviving neurons caused by the severing of fiber tracts and/or the death of subpopulations of neurons sending afferent projections. The mechanism by which chronic partial deafferentation contributes to reactive hyperexcitability is not known. Potential mechanisms of acquired hyperexcitability after injury include perturbations of the neuronal network and alterations of intrinsic neuronal excitability (Prince, 1978). The former encompass alterations in the way neurons are connected and how they interact with one another, without a change in the excitability of the individual neurons. Examples include the aberrant axonal and synaptic reorganization of dentate granule cell mossy fibers (Tauck and Nadler, 1985; Sutula et al., 1989) or CA3 pyramidal cells (McKinney et al., 1997) in epileptogenesis. A failure of synaptic inhibition is another example of a network change favoring epileptogenesis (Sloviter, 1991).

Acquired hyperexcitability may also arise from changes in the intrinsic excitability of individual neurons. Examples of these mechanisms include injury-induced increases in neuronal input resistance (Prince and Tseng, 1993), homeostatic upregulation of glutamate receptor expression (Turrigiano et al., 1998), homeo- 
static upregulation of sodium and calcium channels (Desai et al., 1999), and activity-dependent regulation of potassium channels (Frick et al., 2004) or hyperpolarization-activated cation (h-type) channels (Chen et al., 2001; Shah et al., 2004; Fan et al., 2005).

Determining the locus for the expression of changes in intrinsic excitability is a difficult challenge. Changes in intrinsic excitability of neurons after subcortical white matter transections (Prince and Tseng, 1993) or prolonged application of TTX (Desai et al., 1999) affect the triggering of action potentials by somatic current injection, suggesting that the locus is close to the soma and axon hillock, where action potentials are normally initiated. There is increasing recognition, however, that the dendrite can also be a locus for plasticity of intrinsic excitability (Frick and Johnston, 2005; Magee and Johnston, 2005). Recent demonstrations of seizure-induced regulation of h-type channels (Chen et al., 2001; Shah et al., 2004), which are most highly expressed in thin distal dendrites in pyramidal neurons (Lorincz et al., 2002), shows that these difficult-to-study dendrites are capable of plasticity involving voltage-gated channels. In the present study, we performed experiments to examine changes in the intrinsic excitability of the distal dendrites of CA1 cells after chronic partial deafferentation.

\section{Materials and Methods}

Electrophysiological recording. Hippocampal slice cultures were prepared from 5- to 7-d-old rat pups using the roller tube technique (Gähwiler et al., 1998), following a protocol approved by the University of Maryland School of Medicine Institutional Animal Care and Use Committee. In brief, the hippocampus was dissected free and cut into 400 - $\mu \mathrm{m}$-thick slices on a tissue chopper. Slices were attached to glass coverslips in a film of clotted chicken plasma supplemented with fibrin. The coverslips were then maintained in sealed test tubes containing semisynthetic medium, which were placed on a roller drum in an incubator. Whole-cell recordings were made from CA1 pyramidal cells maintained in vitro for $>14 \mathrm{~d}$. At this point, axonal growth has ceased, dendritic spines have achieved a stable density and shape distribution, and there is no evidence of hyperexcitability in our experience (McKinney et al., 1997, 1999). Pipettes contained (in mM) $135 \mathrm{~K}$-methanesulfate, $10 \mathrm{HEPES}, 10 \mathrm{NaCl}, 1 \mathrm{MgCl}_{2}$, $0.1 \mathrm{~K}_{4}$ BAPTA, $0.01 \mathrm{CaCl}_{2}, 2 \mathrm{Mg}^{2+}$-ATP, and phosphocreatine 10 , adjusted to $\mathrm{pH} 7.3$ with $\mathrm{KOH}$. BAPTA and $\mathrm{CaCl}_{2}$ were not included in the pipette solution in the $\mathrm{Ca}^{2+}$ imaging experiments. In all experiments involving synaptic stimulation (see Figs. 1, 3, 5), KF was substituted for $\mathrm{K}$-methanesulfate in the pipette solution to block $\mathrm{GABA}_{\mathrm{A}}$ receptors in the recorded cell (Smirnov et al., 1999), while leaving inhibition elsewhere in the network intact. The stimulation intensity was set near threshold so that all stimuli evoked small $(<5 \mathrm{mV})$ EPSPs of consistent amplitude, with almost no failures. In our previous work, this weak stimulation was necessary to ensure stimulation of synapses onto single dendritic branches (Cai et al., 2004). The extracellular saline contained (in mM) $145 \mathrm{NaCl}, 3 \mathrm{KCl}, 10 \mathrm{HEPES}, 2 \mathrm{CaCl}_{2}, 1 \mathrm{MgCl}_{2}, 10$ glucose, 0.1 glycine, and 0.25-0.5 Trolox, (to reduce photooxidative damage) adjusted to $\mathrm{pH}$ 7.4. TTX $(1 \mu \mathrm{M})$ was used in experiments involving glutamate photolysis, with the exception of those described in Figure 7. All experiments were performed at room temperature. Fluo3 was used as the calcium indicator because it undergoes a large increase in fluorescence after binding $\mathrm{Ca}^{2+}$ and because of its moderate $K_{\mathrm{d}}$. Calcium transients in the thin terminal dendrites were visualized using $0.5 \mathrm{~mm}$ Fluo3, $100 \mathrm{~ms}$ integration time, and a back-thinned Quantix (Beeston, UK) CCD camera.

Photolysis of caged glutamate. As described previously (Tang, 2006), the 351-364 nm output of an argon ion laser (2017; Spectra-Physics, Mountain View, CA) was launched into a $25-\mu \mathrm{m}$-diameter quartz optical fiber. A relay lens system and a dichroic mirror were used to project the exit end of the optical fiber onto a conjugate of the field diaphragm plane along the epifluorescence path of the microscope. This method creates a spot 3-10 $\mu \mathrm{m}$ in diameter, encompassing a small number of synapses, with an intensity of $1-20 \mathrm{~mW}$ at the end of the fiber. The thinness of hippocampal slice cultures facilitates the present experiments by reducing UV scattering compared with acute tissue slices. The longwavelength fluorescent dye Alexa $568(100 \mu \mathrm{M}$; Molecular Probes, Eugene, OR) was included in the recording pipettes to allow visualization of the fine terminal branches without inadvertent photolysis of the caged

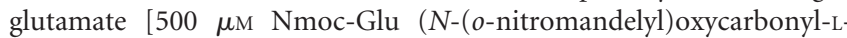
glutamic acid) or $\mathrm{N}$-Ncm-Glu(N-(6-nitro-7-coumarylmethyl)-Lglutamate] (Kao, 2006). The amount of photoreleased glutamate was controlled by varying the UV laser pulse duration with a shutter (NM Laser Products, Sunnyvale, CA). Terminal dendritic segments arising either from the distal apical tuft or oblique branches were studied, with the light targeted at a point in the middle of the dendrite.

Quantitative real-time PCR. The CA1 region was subdissected from whole hippocampal slice cultures in ice-cold culture medium, and 10 CA1 segments were pooled on dry ice for each sample. Three such pooled samples were collected for each time point. Samples were stored at $-80^{\circ} \mathrm{C}$ until further use. RNA was isolated from each sample using TRIzol (Invitrogen, Carlsbad, CA), according to the manufacturer's protocol. Briefly, samples were homogenized in TRIzol, and total RNA was precipitated overnight at $-20^{\circ} \mathrm{C}$. The RNA was then pelleted via centrifugation at $12,000 \times \mathrm{g}$ for $15 \mathrm{~min}$ at $4^{\circ} \mathrm{C}$, washed with $1 \mathrm{ml}$ of $70 \%$ ethanol, and stored at $-80^{\circ} \mathrm{C}$ until use.

Reverse transcription and real-time PCRs (RT-PCRs) were performed using TaqMan reverse transcription and Universal PCR kits (Applied Biosystems, Foster City, CA) according to the manufacturer's protocol. For reverse transcription, the total reaction volume was $20 \mu \mathrm{l}$ and contained the following: $2 \mu \mathrm{l}$ of $10 \times$ TaqMan RT buffer, $4.4 \mu \mathrm{l}$ of $25 \mathrm{~mm}$ $\mathrm{MgCl}_{2}, 4 \mu \mathrm{l}$ of deoxynucleotide triphosphate mixture, $1 \mu \mathrm{l}$ of random hexamers, $0.4 \mu \mathrm{l}$ of RNase inhibitor, $0.5 \mu \mathrm{l}$ of MultiScribe reverse transcriptase, and $0.5 \mu \mathrm{g}$ of total RNA. PCRs were run on a thermal cycler set to $25^{\circ} \mathrm{C}$ for $10 \mathrm{~min}, 48^{\circ} \mathrm{C}$ for $30 \mathrm{~min}$, and $95^{\circ} \mathrm{C}$ for $5 \mathrm{~min}$. For the RT-PCR, the total reaction volume was $30 \mu \mathrm{l}$ and contained the following: $15 \mu \mathrm{l}$ of $2 \times$ TaqMan Universal PCR Master Mix (No AmpErase UNG), $1.5 \mu \mathrm{l}$ of TaqMan Gene Expression Assay Mix [20× mixture of PCR primers and FAM (6-carboxy-fluorescein) dye-labeled TaqMan probe], and $6 \mu \mathrm{l}$ of cDNA. Primers were selected from the Applied Biosystems library and were designed to span the exon boundary and eliminate genomic DNA contamination. Reactions were run for small-conductance calciumactivated potassium channel 2 (SK2) [assay identification number (ID), Rn00570910_m1] and 18S ribosomal RNA (rRNA; assay ID, Hs99999901_s1), as the reference gene, on an MJ Research (Boston, MA) Opticon Monitor set to the following: $95^{\circ} \mathrm{C}$ for $10 \mathrm{~min}$ and 40 cycles of denaturing $\left(95^{\circ} \mathrm{C}\right.$ for $\left.15 \mathrm{~s}\right)$ and annealing/extending $\left(60^{\circ} \mathrm{C}\right.$ for $\left.1 \mathrm{~min}\right)$.

PCR efficiencies and cycle threshold $(\mathrm{Ct})$ were calculated using serial dilutions (1:1, 1:3,1:10,1:30, and 1:100) of pooled control cDNA samples (standards). Cycle threshold was determined by finding the best-fit line from the diluted samples (fit point method). The MJ Research Opticon Monitor analysis software was used to obtain Ct values for each sample. The Ct values of standards were plotted against the relative mRNA abundance for each sample $(500 \mathrm{ng} \times 2 \% \times$ dilution factor $)$. The resultant standard curve was used to calculate the relative mRNA abundance for SK2 and 18S rRNA in each sample. The results were normalized to the reference gene, $18 \mathrm{~S}$ rRNA, and are reported as a ratio of mRNA abundance (SK2/18S rRNA). Values were compared with an unpaired $t$ test.

Western blotting. The CA1 region was subdissected from 10 hippocampal slice cultures in ice-cold culture medium, 10 CA1 regions were pooled into one sample, and samples were sonicated in ice-cold radioimmunoprecipitation assay buffer $(150 \mathrm{~mm} \mathrm{NaCl}, 1 \%$ Triton X-100, $0.1 \%$ SDS, $0.5 \% \mathrm{Na}$ deoxycholate, $50 \mathrm{~mm}$ Tris- $\mathrm{HCl}, 1: 1000$ protease inhibitor cocktail, and $0.2 \% \beta$-mercaptoethanol). As a control for antibody specificity, we also prepared whole-brain homogenates from homozygous SK2 knock-out mice (Bond et al., 2004) and wild-type littermates. Total protein analysis was completed on the supernatant of each sample using the Coomassie protein assay kit according to the manufacturer's protocol (Pierce Biotechnology, Rockford, IL). Each sample, containing $17 \mu \mathrm{g}$ of protein, $1 \times$ sample buffer, and $1 \times$ reducing agent, was loaded into $\mathrm{Nu}-$ PAGE $4-12 \%$ Bis-Tris gels and run in $1 \times$ NuPAGE MES SDS running buffer containing $0.25 \%$ antioxidant (Invitrogen). The gel was transferred onto a polyvinylidene difluoride membrane in $1 \times$ NuPAGE trans- 
fer buffer (containing 10\% methanol and 1\% antioxidant) (Invitrogen). The membrane was blocked overnight at $4^{\circ} \mathrm{C}$ with $5 \%$ nonfat dry milk in buffer containing $1 \mathrm{~m}$ Tris-buffered saline and $0.05 \%$ Tween (TBSTween). The membrane was then probed with $2 \mu \mathrm{g} / \mathrm{ml} \mathrm{SK2}$ antibody (courtesy of J. Adelman, Vollum Institute, Portland, OR) for $1 \mathrm{~h}$ at room temperature. After washing the membrane in TBS-Tween, a horseradish peroxidase-conjugated secondary goat anti-rabbit $\operatorname{IgG}$ (Cell Signaling Technology, Danvers, MA) was applied at 1:10,000 for $1 \mathrm{~h}$ at room temperature. The immunoblot was developed with Pico or Femto chemiluminescent substrate (Pierce Biotechnology). SK2 was detected as a band of $49 \mathrm{kDa}$ in tissue from whole mouse brains and $46 \mathrm{kDa}$ in slice culture tissue. The membrane was stripped in $1 \times$ mild antibody stripping solution (Millipore, Billerica, MA), blocked at room temperature for $1 \mathrm{~h}$, and reprobed with a $\beta$-actin antibody (1:1000; Cell Signaling Technology) overnight at $4^{\circ} \mathrm{C}$. After incubation in 1:10,000 horseradish peroxidaseconjugated goat anti-rabbit IgG (Cell Signaling Technology) for $1 \mathrm{~h}$ at room temperature, the expression of $\beta$-actin was detected using Pico or Femto chemiluminescent substrate (Pierce Biotechnology). Gels were photographed and analyzed using NIH Image software. Data are presented as a ratio of the expression of SK2 to the expression of $\beta$-actin.

\section{Results}

Most excitatory inputs to CA1 pyramidal neurons come from the CA3 region via the Schaffer collateral pathway and from the entorhinal cortex via the temporoammonic pathway. We transected both the Schaffer collateral and temporoammonic pathways in hippocampal slice cultures after $14 \mathrm{~d}$ in vitro with cuts extending from the perimeter of the culture to the hippocampal fissure at each end of area CA1 (Fig. $1 A$ ). Unlesioned sister cultures served as age-matched controls. Fluorescence imaging of dye-filled pyramidal neurons within the isolated CA1 region revealed a substantial decrease in the number of dendritic spines after $7 \mathrm{~d}$ (data not shown), as quantified previously (McKinney et al., 1999), providing positive evidence of partial deafferentation. Preliminary studies were performed to examine the behavior of the residual synapses and the chronic partially deafferented CA1 neurons to local electrical stimulation. Rather than the expected global decrease in electrical excitability, we observed a prolongation of synaptic potentials elicited with brief high-frequency stimulus trains in a number of cells. This prompted us to design specific experiments that could determine whether deafferentation alters excitability by causing a change in presynaptic network mechanisms or intrinsic postsynaptic mechanisms. More specifically, we asked whether excitatory or inhibitory transmission, intrinsic voltage- and $\mathrm{Ca}^{2+}$-gated channels, or transmitter-gated channels were affected after Schaffer collateral and temporoammonic pathway transection.

\section{Partial deafferentation leads to abnormal prolongation of EPSPs}

To isolate EPSPs from inhibitory potentials, potassium fluoride was added to the internal pipette solution to block $\mathrm{GABA}_{\mathrm{A}}$ receptors in the recorded cell (Smirnov et al., 1999). Current-clamp recordings were obtained from CA1 cells while the cells were synaptically stimulated via extracellular electrodes placed in the distal stratum (str.) radiatum of area CA1 within $20 \mu \mathrm{m}$ of a distal dendrite of the cell. Under these conditions, a single electrical stimulus evoked EPSPs whose durations were not significantly different between CA1 cells in control and lesioned slices (Fig. $1 B$, Table 1 ). In contrast, EPSPs evoked by a train of five electrical stimuli given at $50-100 \mathrm{~Hz}$ were significantly prolonged in cells that had been partially deafferented 7-10 d earlier (Fig. $1 B$, Table $1)$. EPSP amplitudes, in contrast, were not different in the lesioned cells compared with control cells for either a single stim-

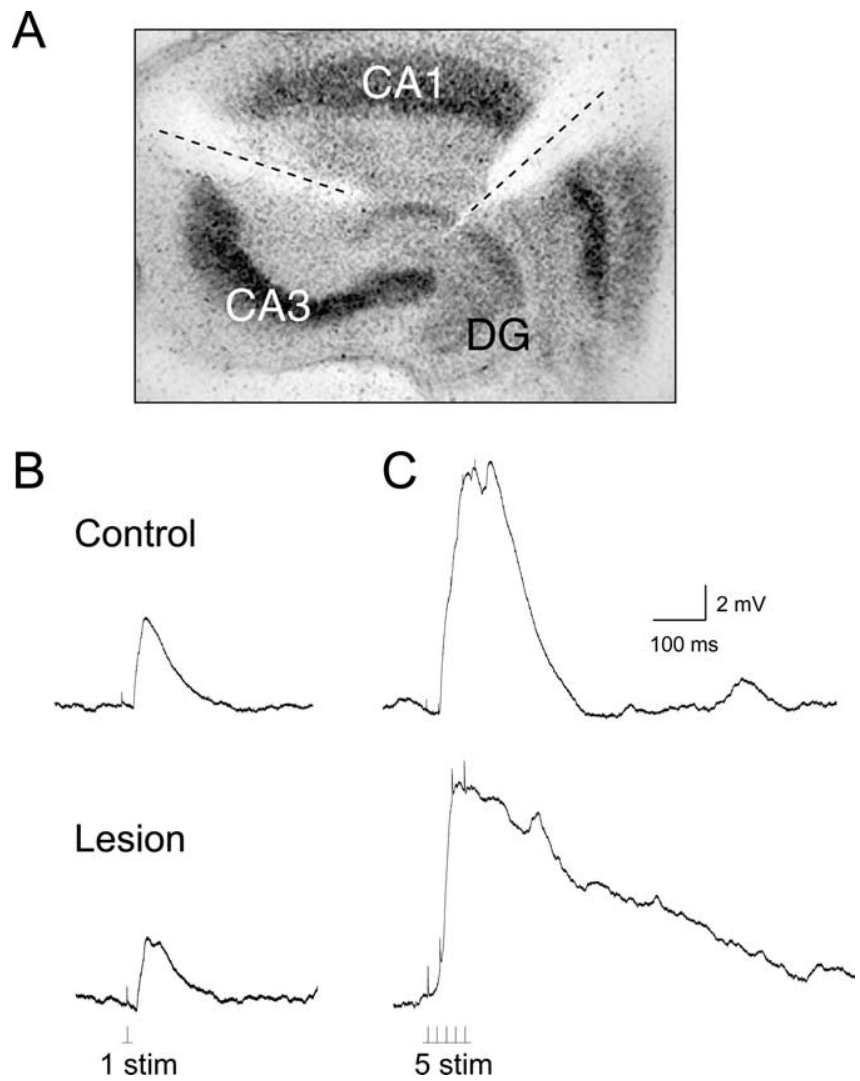

Figure 1. Prolonged excitatory synaptic responses are elicited in CA1 pyramidal cells after Schaffer collateral and perforant path transection. $\boldsymbol{A}$, Image of a Nissl-stained hippocampal slice culture $7 \mathrm{~d}$ after lesion illustrating the sites of transection. $B, C, C A 1$ pyramidal neurons at -70 $\mathrm{mV}$ were stimulated either once $(\boldsymbol{B})$ or five times at $50 \mathrm{~Hz}(\boldsymbol{C})$ in unlesioned (top) or lesioned (bottom) sister cultures. Single stimuli elicited EPSPs of comparable amplitude and duration in deafferented and normally innervated cells. Five stimuli, in contrast, elicited EPSPs that were significantly prolonged in cells from cultures lesioned $7 \mathrm{~d}$ earlier, compared with control cells. DG, Dentate gyrus.

ulus or a train of five stimuli (Table 1). Chronic partial deafferentation thus leads to an alteration in the excitability of cells in area CA1 that is characterized by a selective prolongation of responses elicited with strong, tetanic stimulation.

\section{Partial deafferentation leads to prolonged dendritic plateau depolarization}

The prolongation of tetanus-induced EPSPs in lesioned slices could be caused by a change in presynaptic network-based mechanisms or intrinsic postsynaptic mechanisms. This question was addressed by using focal laser photolysis of caged glutamate. Photorelease of exogenous glutamate allows glutamate receptors on dendrites to be activated directly, thereby avoiding contributions of presynaptic or other network-mediated mechanisms. Brief pulses of UV light were directed onto individual terminal dendritic segments that were spatially well isolated from neighboring branches, as described previously (Wei et al., 2001). The strength of direct dendritic stimulation was varied by changing the duration of the laser pulse. In response to brief ( $2 \mathrm{~ms})$, low-intensity ( 1 $\mathrm{mW}$ within a 5 - $\mu \mathrm{m}$-diameter spot) laser pulses, small depolarizations [photolysis-induced EPSPs (ph-EPSPs)] resembling unitary EPSPs were elicited in both control and partially deafferented dendrites (Fig. 2). These ph-EPSPs were subthreshold for initiation of plateau potentials (Wei et al., 2001; Cai et al., 2004). We observed no significant difference in the peak ph-EPSP am- 
Table 1. Prolonged glutamatergic synaptic responses in lesioned cultures

\begin{tabular}{llllllll}
\hline & One stimulus & & & & Five stimuli & & \\
\cline { 2 - 4 } & Unlesioned & Lesioned & Unlesioned with DNQX/AP5 & & Unlesioned & Lesioned & Unlesioned with DNQX/AP5 \\
\hline Amplitude $(\mathrm{mV})$ & $4.1 \pm 1.0$ & $2.7 \pm 0.6$ & $3.3 \pm 0.9$ & & $10.4 \pm 1.7$ & $12.5 \pm 2.0$ & $14.9 \pm 2.4$ \\
Duration (ms) & $103 \pm 25$ & $103 \pm 15$ & $91 \pm 23$ & & $172 \pm 47$ & $723 \pm 335^{*}$ & $378 \pm 130^{* *}$ \\
\hline
\end{tabular}

Amplitude and duration at half-maximal amplitude for responses recorded from CA1 pyramidal cells in response to local synaptic stimulation in control, unlesioned cultures ( $n=7$ cells), cultures lesioned $7 \mathrm{~d}$ earlier ( $n=8$ cells), and unlesioned cultures pretreated with DNQX and AP5 for $7 \mathrm{~d}\left(n=6\right.$ cells). *Significantly longer than the response to five stimuli at 50 or $100 \mathrm{~Hz}$ in unlesioned cultures $\left(p<0.01\right.$; Mann-Whitney $U$ test). ${ }^{* *}$ Significantly longer than the response to five stimuli at $50-100 \mathrm{~Hz}$ in unlesioned cultures $(p<0.05$; Mann-Whitney $U$ test). Other values are not significantly different from unlesioned cultures (Mann-Whitney $U$ test). Cells were held at $-70 \mathrm{mV}$ using (sF-filled patch pipettes.
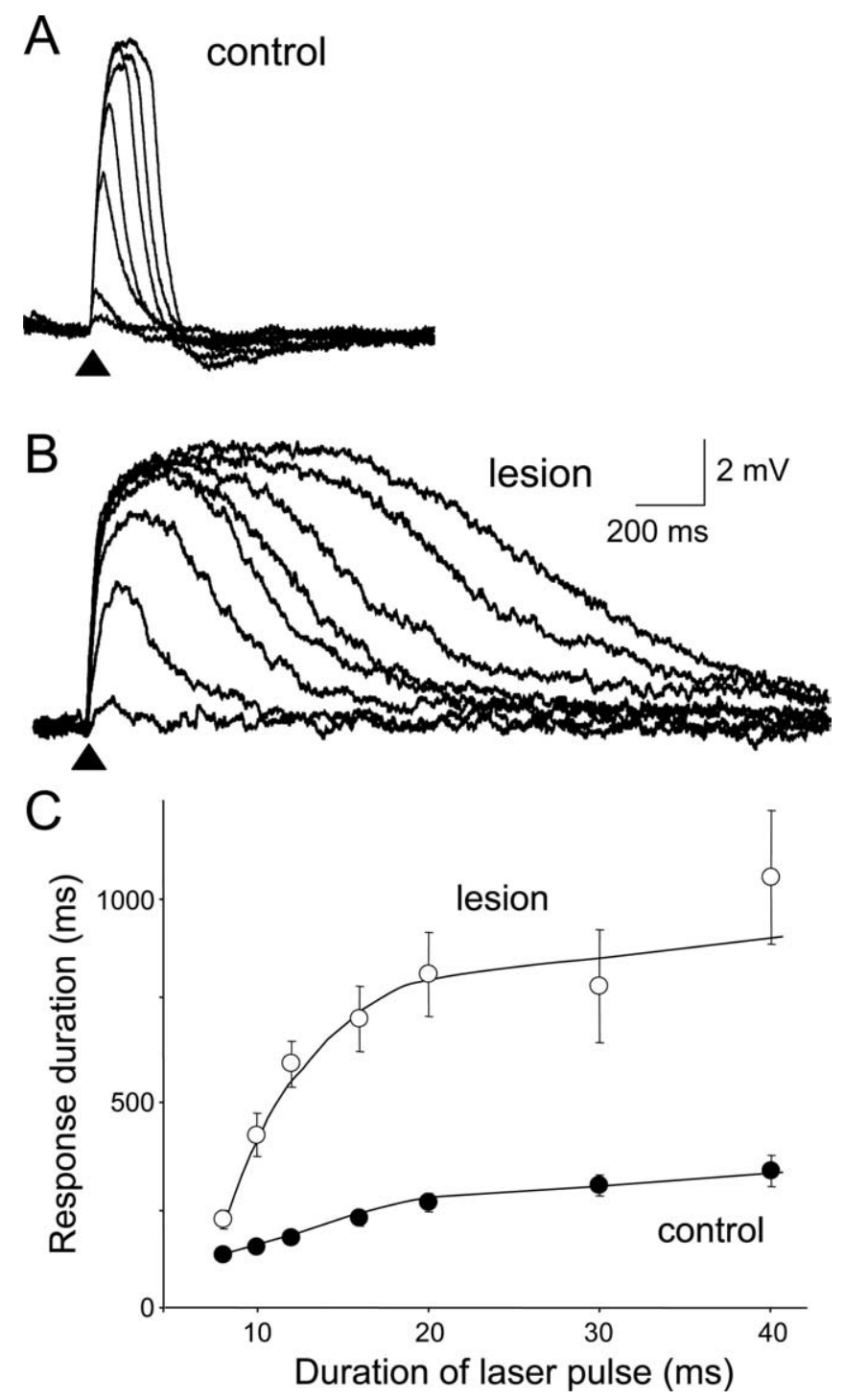

Figure 2. Prolongation of dendritic plateau potentials after partial deafferentation. $\boldsymbol{A}, \boldsymbol{B}$, Responses elicited by microphotolysis of caged glutamate onto a distal dendrite of a control $(\boldsymbol{A})$ and a deafferented $(\boldsymbol{B})$ CA1 pyramidal neuron using a series of laser pulses of increasing duration. Note the marked increase in the duration of the responses after deafferentation. $V_{\mathrm{m}}=$ $-70 \mathrm{mV}$. C, Summary plot of the relationship between the strength of photostimulation, as determined by the duration of the laser pulse, and the duration of the depolarizing response, measured at the half-maximal amplitude, in normally innervated $(\mathbf{O}$ and chronically deafferented $(O)$ cells. The lines were drawn by eye. Error barsindicate SEM.

plitudes in control and deafferented cells (Table 2). Their decay time constants were also not significantly different (Table 2).

Stronger photostimulation, in contrast, revealed a striking difference in the responses from control and deafferented cells. We have shown previously that strong dendritic stimulation, produced by brief high-frequency tetani for synaptic stimulation
Table 2. GABAergic inhibition and postsynaptic glutamate receptor function are unchanged in lesioned cultures

\begin{tabular}{lcc}
\hline & Unlesioned & Lesioned \\
\hline SIPSC frequency (Hz) & $13.8 \pm 1.6(9)$ & $14.1 \pm 2.2(6)$ \\
sIPSC amplitude (pA) & $49.6 \pm 12.7(9)$ & $41.8 \pm 11.9(6)$ \\
Evoked IPSC amplitude (pA) & $102 \pm 38(7)$ & $130 \pm 35(8)$ \\
ph-EPSP amplitude (mV) & $2.2 \pm 0.2(14)$ & $2.0 \pm 0.2(10)$ \\
ph-EPSP decay time constant (ms) & $72.2 \pm 3.7(14)$ & $71.7 \pm 4.9(10)$ \\
ph-NMDA-EPSP amplitude (mV) & $2.5 \pm 0.7(13)$ & $2.7 \pm 0.6(15)$ \\
ph-NMDA-EPSP decay time constant (ms) & $252.1 \pm 90.2(13)$ & $265.2 \pm 63.2(15)$ \\
\hline
\end{tabular}

The number of observations is given in parentheses. Spontaneous IPSCS (IIPSCs) were recorded in saline containing $20 \mu \mathrm{m} \mathrm{DNQX}$ and $40 \mu \mathrm{m}$ AP5. Evoked IPSCs were elicited with a $20 \mu$ A stimulus delivered to str. radiatum within 50 $\mu \mathrm{m}$ of the recorded cell in the presence of $20 \mu \mathrm{m}$ DNQX and $40 \mu \mathrm{mAPS}$. ph-EPSPs were elicited with a 2 ms laser pulse duration and identical laser intensity in control saline or in $\mathrm{Mg}^{2+}$-free saline in the presence of $20 \mu \mathrm{M} \mathrm{DNQX}$ (ph-NMDA-EPSP). There were no statistically significant differences between lesioned and unlesioned cultures for any response.

or by longer-duration laser pulses for photostimulation, elicits plateau potentials in terminal dendrites of CA1 pyramidal cells (Wei et al., 2001; Cai et al., 2004). The duration of these plateau potentials in normally innervated neurons increases only slightly as the photostimulation intensity is progressively increased (Wei et al., 2001) (Fig. 2, top). In partially deafferented cells, in contrast, we found that increasing strength of stimuli resulted in plateau potentials with significantly prolonged durations, up to threefold greater (Fig. 2, middle) $(p<0.001$; mixed two-way ANOVA with Greenhouse-Geiser correction on repeated factor). Post hoc analyses indicated that the differences in duration were only significant for laser pulse durations $\geq 10 \mathrm{~ms}$ (Bonferroni correction). Pooled data are shown in Figure 2 (bottom). Plateau potential amplitudes, in contrast, were not different in lesioned and unlesioned cultures $(8.9 \pm 0.5 \mathrm{mV}$ in control vs $8.4 \pm 0.3 \mathrm{mV}$ after deafferentation; $n=23$ each with 20 ms laser pulse duration; $p>0.05$; unpaired $t$ test).

NMDA receptors are normally activated by strong stimuli and are important for the triggering of dendritic plateau potentials (Wei et al., 2001). Conceivably, the increased duration of tetanusevoked EPSPs and plateau potentials in deafferented cells could be caused by changes in the number or kinetics of NMDA receptors. NMDA receptor function was therefore assayed by eliciting photolytic responses to brief laser pulses $(2 \mathrm{~ms})$ at $-70 \mathrm{mV}$ in nominally $\mathrm{Mg}^{2+}$-free saline containing $20 \mu \mathrm{M}$ DNQX. The amplitude and decay time constant of these NMDA responses were statistically identical in control and lesioned cultures (Table 2). We could thus detect no evidence of significant changes in the number or kinetics of NMDA receptors expressed on distal dendrites after partial deafferentation.

In summary, responses elicited from distal dendrites of lesioned cells using either tetanic synaptic stimulation or strong direct glutamatergic stimulation were markedly prolonged, compared with unlesioned cells. Responses elicited with weak stimulation, in contrast, were the same. Because direct dendritic stimulation with photoreleased glutamate bypasses presynaptic mechanisms, we conclude that a change in postsynaptic excitability alone is sufficient for the expression of deafferentation- 
induced prolongation of synaptic responses. In addition, the absence of differences in the amplitude of ph-EPSPs or synaptic EPSPs, when elicited with weak stimulation, in lesioned and unlesioned cells makes it unlikely that partial deafferentation caused a substantial increase in the expression of glutamate receptors. Furthermore, because the duration of these EPSPs and ph-EPSPs was not significantly different in deafferented and normally innervated neurons, it is unlikely that chronic deafferentation induced a change in the kinetics of synaptic glutamate receptors or the passive electronic properties of the dendrites themselves. We next considered the possibility that modifications of intrinsic conductances rather than glutamate receptors may be the principal mechanism responsible for the deafferentation-induced changes in dendritic excitability.

\section{Role of $\mathrm{Ca}^{2+}$-activated SK-type $\mathrm{K}^{+}$channels}

We have reported previously that a major contributor to the repolarization of dendritic plateau potentials is the apaminsensitive SK-type $\mathrm{Ca}^{2+}$-activated $\mathrm{K}^{+}$channel (Cai et al., 2004). Selective blockade of these channels prolongs responses to strong photostimulation (Cai et al., 2004). Thus, one possible mechanism for the aberrant excitability after chronic partial deafferentation is a downregulation of SK channel function. If this is the case, then there are three predictions. First, the ability of apamin to prolong the duration of the dendritic response to strong synaptic or photolytic stimulation should be occluded after partial deafferentation, because apamin and chronic partial deafferentation would act through a shared molecular mechanism. Second, high concentrations of tetraethylammonium (TEA; $10 \mathrm{~mm}$ ), which also blocks SK channels (Storm, 1989; Cai et al., 2004), should behave qualitatively like apamin. Third, intracellular dialysis of the $\mathrm{Ca}^{2+}$ chelator BAPTA from the recording pipette solution, which prolongs plateau potentials in normally innervated cells by preventing activation of SK channels (Cai et al., 2004), should be less effective in deafferented cells.

To test these predictions, extracellular stimulating electrodes placed near the distal dendrites of recorded cells, as described above, were used to evoke EPSPs and plateau potentials. In unlesioned cells, bath-applied apamin (200 nM) increased the duration of responses elicited with trains of five stimuli at $50-100 \mathrm{~Hz}$ by $86 \pm 34 \%$ ( $p<0.05$; paired $t$ test; $n=6$ cells) (Fig. $3 A$, top traces). This indicates that the train of five pulses was sufficiently strong to activate SK channels on the distal dendrite in control neurons (Ngo-Anh et al., 2005) and that their blockade can mimic the EPSP prolongation observed in partially deafferented cells. In contrast, apamin produced no significant effect on the duration of responses elicited with five stimuli in partially deafferented cells (Fig. 3B, top traces) [mean change in duration $=$ $8 \pm 14 \% ; p>0.05$; paired $t$ test; $n=8$ cells (Fig. $3 C$ )]. This observation confirms the first prediction that partial deafferentation will occlude the action of apamin on EPSP duration after strong stimulation. Apamin had no significant effects on the amplitude or duration of EPSPs evoked with a single electrical stimulus in either control or partially deafferented cells (Fig. 3A-C). Next, the prediction that high concentrations of TEA would mimic the actions of apamin on plateau potentials elicited with photostimulation in control cells, but be occluded in deafferented cells, was tested and confirmed. Plateau potential duration is prolonged 2.75-fold by $10 \mathrm{~mm}$ TEA in control cells (Cai et al., 2004), but TEA had no significant effect on plateau potential duration in deafferented cells $(13 \pm 11 \% ; n=10$ cells; paired $t$ test). Finally, plateau potential duration is prolonged 2.9 -fold in control cells after $30 \mathrm{~min}$ of recording with pipettes containing 10

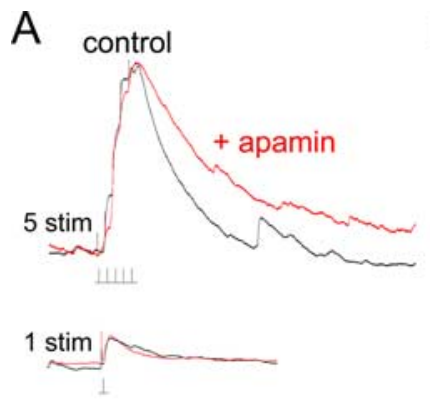

B lesion

C
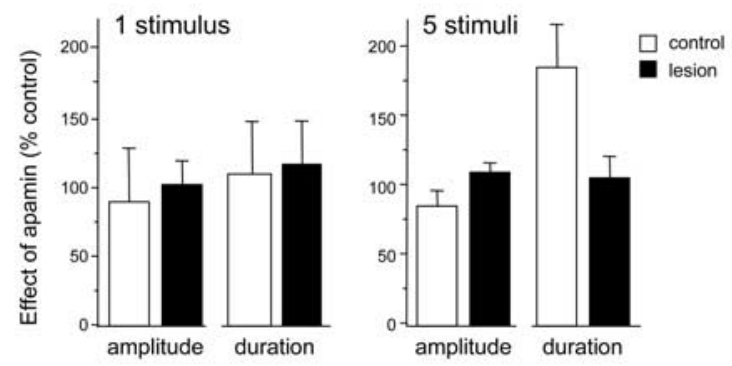

$\mathrm{D}$

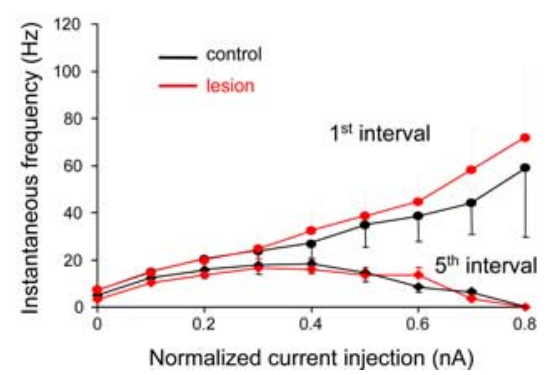

Figure 3. Synaptic responses are prolonged after partial deafferentation resulting from downregulation of dendritic $\mathrm{Ca}^{2+}$-activated $\mathrm{K}^{+}$channels. $A, B, C \mathrm{~A} 1$ pyramidal neurons at $-70 \mathrm{mV}$ were stimulated either once (bottom) or five times at $50 \mathrm{~Hz}$ (top) before (black traces) and after (red traces) application of $200 \mathrm{~nm}$ apamin in unlesioned $(\boldsymbol{A})$ or lesioned $(\boldsymbol{B})$ sister cultures. C, Summary of the effects of apamin on excitatory synaptic potentials (as a percentage change from initial amplitude and duration) in normally innervated (white bars; $n=6$ ) and deafferented (solid bar; $n=8$ ) cells. $\boldsymbol{D}$, Slow-AHP-mediated spike frequency accommodation of evoked action potential discharge is not altered after deafferentation. The instantaneous firing frequency of $\mathrm{CA} 1$ cells, determined with $1 \mathrm{~s}$ depolarizing current pulses of varying amplitude and normalized to action potential threshold, is shown for the first (circles) and fifth (diamonds) action potential interval for control (black; $n=18$ ) and deafferented (red; $n=19$ ) cells. Error bars indicate SEM.

mM BAPTA (Cai et al., 2004) but only $35 \pm 19 \%$ in deafferented cells $(n=6$ cells).

$\mathrm{Ca}^{2+}$-activated $\mathrm{K}^{+}$current carried by SK channels contributes to the so-called medium-duration afterhyperpolarization (mAHP), which lasts for 50-100 ms after trains of action potentials elicited with somatic depolarizing current steps (Storm, 1989; Sah and Faber, 2002; Bond et al., 2004). To further test the hypothesis that SK channels may be downregulated in deafferented cells, we compared the maximum amplitude of the mAHP in control and deafferented neurons. There was a significant decrease in the mAHP amplitude in deafferented cells compared with normally innervated cells $(8.3 \pm 0.9$ vs $4.5 \pm 0.9 \mathrm{mV} ; n=24$ and 21 cells, respectively; unpaired $t$ test; $p<0.01$ ).

Could a decrease in dendritic SK channel function underlie the decrease in action potential-evoked mAHP? We tested this hypothesis by focally applying apamin $(1 \mu \mathrm{M})$ in distal dendritic regions by pressure pulse from a patch pipette while eliciting action potentials with depolarizing current injection. We found that the mAHP after trains of 3-5 action potentials (measured as above) was reduced 
significantly after local apamin application (supplemental Fig. 1, available at www.jneurosci.org as supplemental material). We conclude that dendritic SK channels contribute to the action potential-evoked mAHP as recorded from the soma.

We next asked whether other, non-SKtype $\mathrm{Ca}^{2+}$-activated $\mathrm{K}^{+}$channels were also affected by deafferentation by measuring spike frequency adaptation. Action potentials were elicited with $1 \mathrm{~s}$ depolarizing current steps of varying amplitude in control and deafferented CA1 cells, and their instantaneous frequency was plotted as a function of the amplitude of the current step. The increase in the interval between action potentials during maintained firing, apparent as a decrease in the instantaneous firing frequency, is attributable to activation of $\mathrm{Ca}^{2+}$-activated $\mathrm{K}^{+}$ channels of the so-called slow-AHP type (Madison and Nicoll, 1984). No significant difference in the time interval between the first and second action potentials or the fifth and sixth action potentials between lesioned and control cells was observed (Fig. 3D), indicating that slowAHP-type channel function was not different in control and lesioned cells. We thus conclude that the medium AHP is selectively affected by chronic partial deafferentation.

Together, these data provide both direct and indirect evidence of a downregulation of SK-type $\mathrm{Ca}^{2+}$-activated $\mathrm{K}^{+}$ channel function after partial deafferentation and, consequently, a decreased dendritic repolarization in response to strong stimuli.

\section{Alternative mechanisms cannot explain prolongation of dendritic response}

Plateau potentials in normally innervated dendrites are blocked by the voltage-dependent $\mathrm{Ca}^{2+}$ channel blocker $\mathrm{Cd}^{2+}$ and the NMDA receptor antagonist $\mathrm{D}, \mathrm{L}-2$-amino-5-phosphonopentanoic acid (AP5) (Wei et al., 2001). Could the prolonged responses in deafferented dendrites be caused by recruitment of new classes of inward currents or by aberrant spread of depolarization into neighboring dendritic compartments? Experiments were performed to test these hypotheses. As in normally innervated cells, the dendritic depolarization triggered by $10 \mathrm{~ms}$ photolytic laser pulses in deafferented CA1 cells was strongly reduced either by $25-50 \mu \mathrm{M} \mathrm{Cd}^{2+}$ ( $n=5$ of 5 cells) or by $100 \mu \mathrm{M}$ AP5 ( $n=4$ of 4 cells), leaving an exponentially decaying EPSP (Fig. 4A,B). Similarly, the increased fluorescence emission of the $\mathrm{Ca}^{2+}$ indicator Fluo3 triggered by $\mathrm{Ca}^{2+}$ influx during the dendritic plateau potentials remained localized to a single dendritic compartment in deafferented CA1 cells, as in control cells, stopping at the first major branch point proximal to the site of photolysis ( $n=12$ of 14 cells) or short of the branch point ( $n=2$ of 14 cells) (Fig. 4C). The maximal amplitude of the Fluo3 fluorescence achieved at the end of the plateau potentials was increased significantly in lesioned cells, however (control $\Delta F / F=7.0 \pm 1.4 \%$ vs lesion $=11.8 \pm 1.8 \% ; n=13$ and $14 ; p<0.05$ ). This result is consistent with an increase in $\mathrm{Ca}^{2+}$ influx as a result of the prolon-
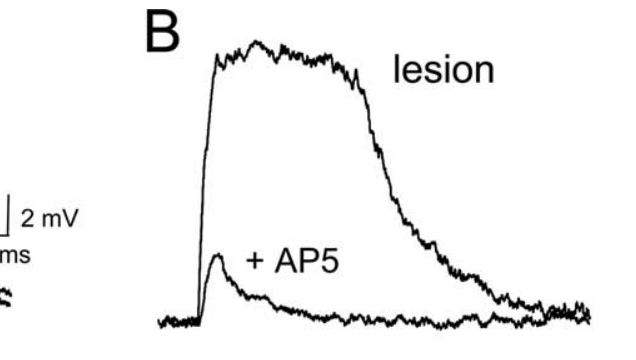

Fluo-3

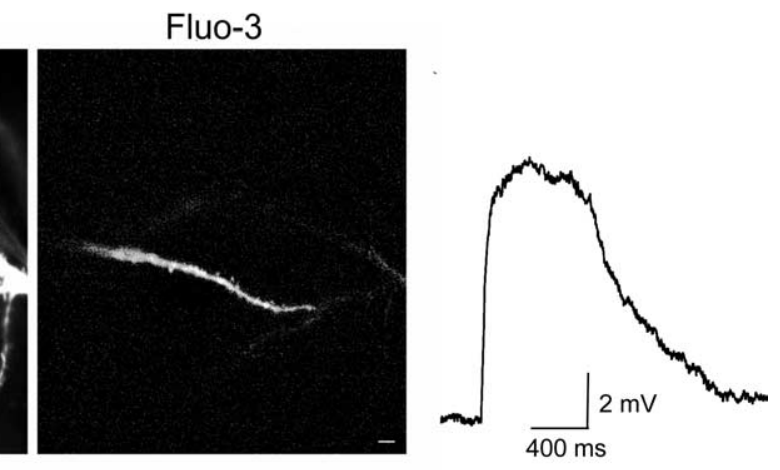

$400 \mathrm{~ms}$

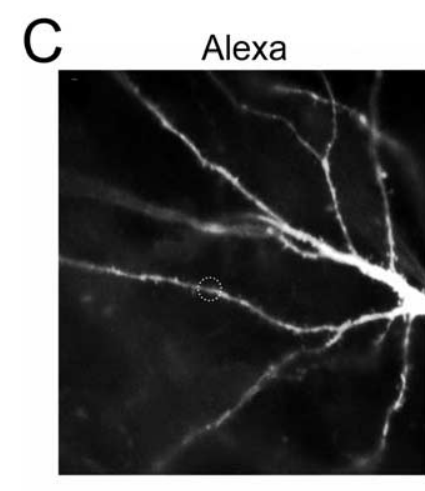

Figure 4. Prolonged plateau potentials in partially deafferented cells are mediated by NMDA receptor-dependent activation of voltage-dependent $\mathrm{Ca}^{2+}$ channels and remain confined to a single distal dendrite after partial deafferentation. In a CA1 cell from

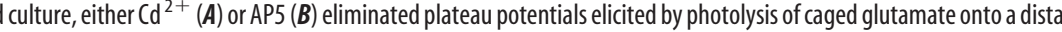
(Wei et al., 2001). The image was produced by digitally subtracting an image taken immediately before gation of the responses and the increase in the time the local NMDA and voltage-dependent $\mathrm{Ca}^{2+}$ channels remain open.

Many forms of hyperexcitability result from decreased GABAergic synaptic inhibition, including in some models of chronic injury (Li and Prince, 2002). Could the aberrant excitability after synaptic stimulation be attributable to decreased inhibition? The amplitude and frequency of spontaneous IPSCs were recorded from CA1 cells in saline containing $20 \mu \mathrm{M}$ DNQX and $40 \mu \mathrm{M}$ AP5. No significant difference in either the amplitude or frequency of spontaneous IPSCs was observed between lesioned and unlesioned cultures (Table 2). Similarly, the amplitude of evoked monosynaptic IPSCs was not significantly different in lesioned and unlesioned cultures (Table 2). We conclude that hyperexcitability after deafferentation is not accompanied by a gross decrease in synaptic inhibition.

In chronically injured neocortex, hyperexcitability is correlated with changes in neuronal input resistance and facilitation of highfrequency action potential discharge (Prince and Tseng, 1993). Could deafferentation-induced aberrant excitability be attributable to similar changes in these intrinsic properties? Basic electrophysiological parameters and properties of action potentials evoked with somatic current injection were examined in cells from control hippocampal cultures and sister cultures lesioned $7 \mathrm{~d}$ earlier. No significant differences in input resistance or action potential amplitude, rise time, threshold, and latency were found (Table 3 ).

\section{Chemical deafferentation also prolongs dendritic plateau potentials}

What consequence of partial deafferentation triggers changes in cellular excitability? If prolongation of plateau potentials after 
Table 3. Electrophysiological parameters in CA1 cells are unchanged in lesioned cultures

\begin{tabular}{lcc}
\hline & \multicolumn{1}{c}{ Unlesioned } & \multicolumn{1}{l}{ Lesioned } \\
\hline Input resistance $(\mathrm{M} \Omega)$ & $111 \pm 31(23)$ & $157 \pm 50(25)$ \\
Action potential amplitude $(\mathrm{mV})$ & $82.6 \pm 2.4(23)$ & $82.8 \pm 1.6(17)$ \\
Action potential rise time $(\mathrm{ms})$ & $0.67 \pm 0.05(23)$ & $0.62 \pm 0.03(17)$ \\
Action potential threshold $(\mathrm{mV})$ & $-37.9 \pm 1.2(23)$ & $-41.7 \pm 1.5(17)$ \\
Action potential latency $(\mathrm{ms})$ & $313.9 \pm 35.9(21)$ & $372 \pm 64.8(13)$ \\
\hline
\end{tabular}

The number of observations is given in parentheses. Input resistance was determined from the voltage deflection produced by $150 \mathrm{~ms},-50 \mathrm{pA}$ current pulses. Action potential parameters were determined from just suprathreshold responses to $500 \mathrm{~ms}$ depolarizing current pulses. Latency was determined for the smallest amplitude $500 \mathrm{~ms}$ depolarizing current pulse eliciting an action potential. There were no significant differences in any parameter between lesioned and unlesioned cultures.

deafferentation is triggered homeostatically by a decrease in overall synaptic activity level, then blocking glutamate receptors pharmacologically (i.e., chemical deafferentation) should elicit a comparable effect. To test this hypothesis, organotypic hippocampal cultures were maintained in vitro for $14 \mathrm{~d}$ and then treated with a combination of AMPAR and NMDAR antagonists $(40 \mu \mathrm{M}$ DNQX plus $80 \mu \mathrm{M}$ AP5). The antagonists were then washed out acutely, and responses to photostimulation were elicited. After $7 \mathrm{~d}$ in glutamate receptor antagonists, we observed a significant prolongation in the duration of dendritic plateau potentials in response to photolysis of caged glutamate onto distal terminal dendrites, but no significant change in their amplitude (Fig. 5A). As in the lesioned cultures, there was also no significant change in the amplitude or duration of small subthreshold responses. There was also no difference in the nonlinear relationship between stimulation intensity and response amplitude (Fig. $5 B$ ), indicating that the plateau potential threshold was not different after deafferentation. We also tested whether responses to synaptically released glutamate were altered after DNQX and AP5 treatment (Fig. 5C). As in the lesioned cultures, we found that there was no significant difference in single, synaptically evoked EPSPs between control and drug-treated cultures; however, responses to a train of five synaptic stimuli at $50-100 \mathrm{~Hz}$ were significantly prolonged (Table 1). This form of chemical deafferentation thus results in a phenotypic alteration in the electrophysiology of CA1 cell dendrites remarkably similar to that observed with physical deafferentation, suggesting that it is a decrease in the overall activity level in the cell that leads to the increase in its excitability.

We used the homogenous block of activity produced by chemical deafferentation to assay the time course of plateau potential prolongation. Responses to photolysis of caged glutamate were compared in cultures treated with DNQX and AP5, as above, and untreated controls. We observed that plateau potential duration increased progressively over $6 \mathrm{~d}$ after the start of treatment, becoming significant after $3 \mathrm{~d}$ (supplemental Fig. 2, available at www.jneurosci.org as supplemental material).

Because nerve terminals remain intact after DNQX and AP5 treatment, we could compare the mean amplitude of spontaneous miniature EPSCs (mEPSCs) in these cultures to control cultures. Whole-cell voltage-clamp recordings were made from CA1 pyramidal cells in cultures chronically treated with DNQX and AP5 for $7 \mathrm{~d}$ and in control sister cultures of the same age. The mean amplitude of mEPSCs in DNQX and AP5-treated cultures $(13.2 \pm 0.3 \mathrm{pA} ; n=5)$ was not significantly different from that in control cultures (12.6 $\pm 0.4 \mathrm{pA} ; n=5)$. Together with the comparable amplitude of small ph-EPSPs, these findings suggest that prolongation of plateau potentials can occur independently from changes in AMPA receptor expression.

\section{SK2 mRNA and protein levels are not altered} by deafferentation

The downregulation of SK-type $\mathrm{Ca}^{2+}$-activated $\mathrm{K}^{+}$channel function after physical and chemical deafferentation could result from decreased SK channel expression or from posttranslational modification of existing channels. We used quantitative real-time PCR to distinguish between these possibilities. Area CA1 was isolated, and RNA was harvested from control cultures, cultures lesioned $7 \mathrm{~d}$ earlier, and cultures treated for $7 \mathrm{~d}$ with DNQX and AP5 as above. No significant differences in mRNA expression for the predominant hippocampal SK channel type, SK2 (Bond et al., 2004), were detected (Fig. 6A). Similarly, Western blotting was used to compare SK2 protein levels in control and lesioned slice cultures. Using an antibody that clearly distinguishes between wild-type and SK2 $2^{-1-}$ mouse brain tissue (Fig. $6 B$ ), we found no significant difference in SK2 expression in cultures treated with DNQX and AP5 for $7 \mathrm{~d}$ or in cultures that had undergone a Schaffer collateral transection $7 \mathrm{~d}$ earlier, compared with control cultures (Fig. 6C,D). We suggest that decreased SK channel function after deafferentation and inactivity results from a posttranslational modification of the channels.

\section{Aberrant responses in distal dendrites increase neuronal excitability}

The ability of focal glutamate photostimulation to trigger a propagated action potential in a CA1 pyramidal neuron is site specific in unlesioned hippocampal slice cultures (Wei et al., 2001). In the absence of TTX, photostimulation of terminal apical dendrites or oblique dendrites at sufficient intensity to elicit plateau potentials almost never ( $n=0$ of 24 and 2 of 13 dendrites, respectively) elicited action potentials in unlesioned cultures. This is consistent with the observation that even very strong electrical stimulation of the temporoammonic pathway, the main afferent to the distal apical tuft dendrites in CA1 neurons, does not readily elicit somatic action potentials (Jarsky et al., 2005). We have shown previously that pharmacologically induced prolongation of plateau potentials facilitates action potential initiation (Cai et al., 2004). We therefore asked whether the deafferentation-induced prolongation of plateau potentials also affected the initiation of action potentials. Indeed, 1 week after deafferentation, photostimulation at the same intensity directed onto individual terminal apical ( 13 of 15 CA 1 dendrites) or oblique ( 7 of 8 dendrites) dendrites readily elicited fast action potentials (Fig. $7 A, B$ ). If, in contrast, the site of focal photolysis was directed at the base of the apical tuft, at which distal branches converge onto the primary apical trunk, a majority of both control (18 of 21) and deafferented (12 of 12 cells) dendrites generated either single action potentials or bursts of action potentials. The enhanced ability of strong photostimulation of distal apical dendrites to trigger action potentials can be attributed to prolongation of the plateau potential, because application of apamin (Cai et al., 2004) or 10 mM TEA (Fig. 7C) to control cells produced an identical effect. Prolongation of distal dendritic glutamate responses is thus accompanied by facilitated induction of action potential discharge.

\section{Discussion}

Approximately 1,500,000 people suffer a traumatic brain injury each year in the United States, resulting in almost 100,000 patients per year with long-term disabilities. Although the disabilities of a majority of these patients are directly related to neuronal death and loss of function, a significant subset develop conditions of aberrant neuronal excitability. The pathophysiological mechanisms responsible for neuronal hyperexcitability remain poorly 
understood. Their study has been hampered because multiple reactive processes are activated simultaneously after brain injury. In the face of this complexity, we have taken a reductionist approach and focused on one fundamental consequence of lesions that is common to many forms of traumatic brain injury: neuronal deafferentation. We developed an in vitro model of traumatic brain injury that takes advantage of the cellular organization of the hippocampus and allows for the transection of the primary afferent inputs to area CA1.

Using this model, we have demonstrated that chronic partial deafferentation of CA1 cells, resulting from the transection of afferent pathways, results in (1) the delayed emergence of prolonged excitatory synaptic responses with stimulation of residual afferent fibers (Fig. 1), (2) an increase in dendritic excitability, apparent as a marked prolongation of responses of distal dendrites to microphotolysis of caged glutamate (Fig. 2), and (3) an increase in the likelihood that excitation of single distal dendritic branches successfully elicits fast action potentials (Fig. 7). Hyperexcitability has been demonstrated previously with in vitro and in vivo models of decreased activity, including TTX infusion (Galvan et al., 2000) and neocortical isolation (Prince and Tseng, 1993; Nita et al., 2006), and our observation of prolonged synaptic depolarizations are consistent with these studies. Unfortunately, the evidence of axon collateral sprouting (Salin et al., 1995) and changes in GABAergic inhibition (Prince and Tseng, 1993; Yang and Benardo, 1997; Li and Prince, 2002) in these models renders the distinction between presynaptic and postsynaptic mechanisms difficult.

We found that the effects of Schaffer collateral transection were mimicked by blocking SK channels acutely in control slices. Because the aberrant dendritic behavior in lesioned slices occluded the effects of SK channel blockers, and because the medium AHP was reduced in lesioned slices, we suggest that downregulation of SK-type $\mathrm{Ca}^{2+}$-activated $\mathrm{K}^{+}$channel function plays an important role in the expression of aberrant excitability of distal dendrites after chronic partial deafferentation. This process is relatively slow, taking approximately 1 week to become apparent. We found that decreased SK channel function was not accompanied by a change in the level of protein or mRNA of the predominant hippocampal SK channel isoform, SK2 (Bond et al., 2004). We suggest, therefore, that the function of dendritic SK2 channels is decreased after deafferentation as a result of some posttranslational modification. An attractive hypothesis is that the phosphorylation of calmodulin, the $\mathrm{Ca}^{2+}$ sensor for SK channel activation, by the kinase casein kinase 2 has increased as a result of the deafferentation or block of synaptic activity, resulting in a decrease in its affinity for $\mathrm{Ca}^{2+}$ and, thereby, a decrease in the probability of SK channel opening after a plateau potential (Bildl et al., 2004). Alternatively, changes in SK2 channel phosbars indicate SEM.
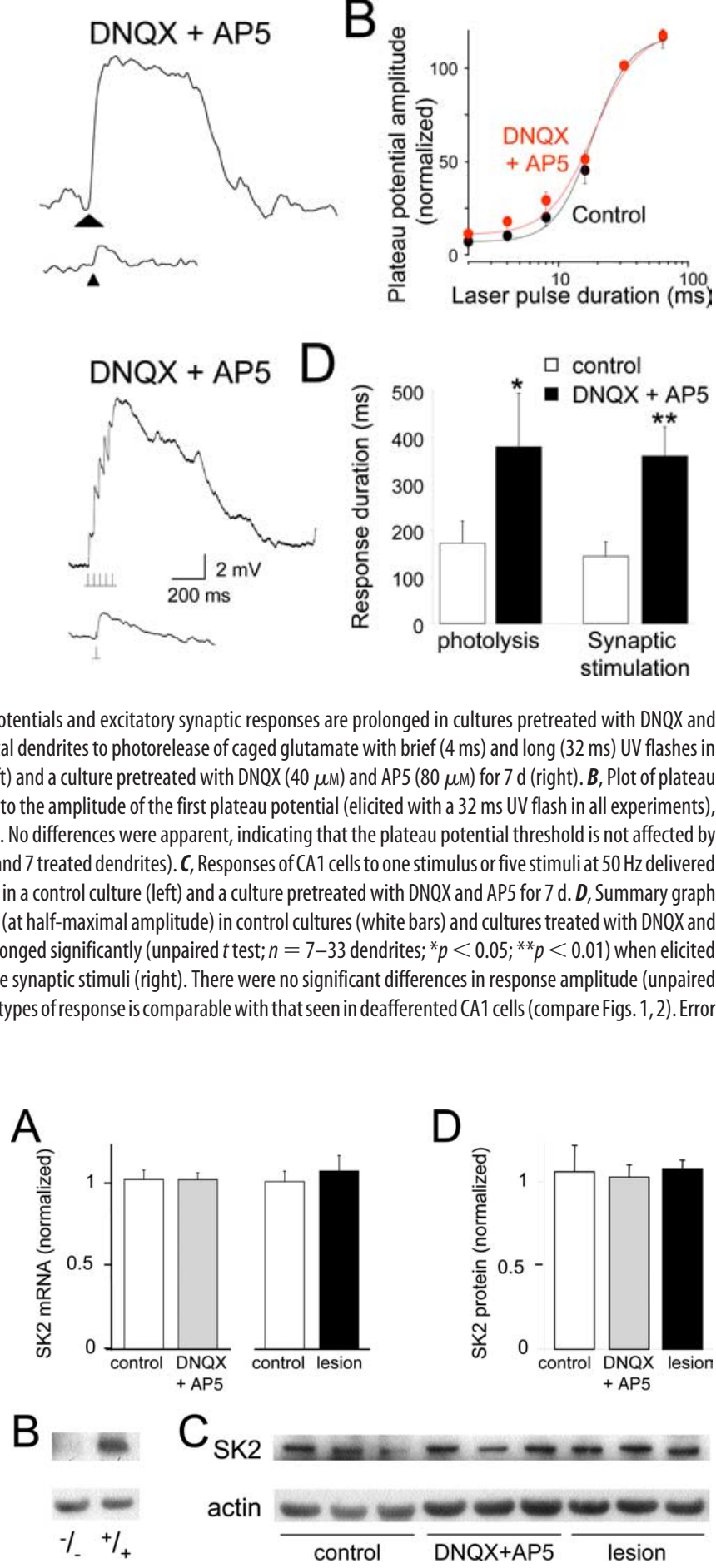

stimulation
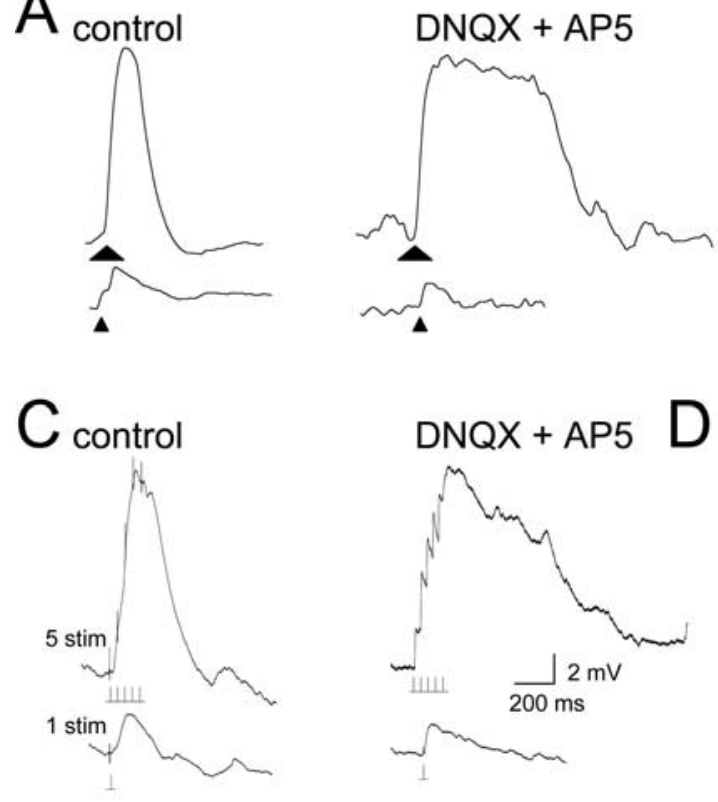

Figure 5. Dendritic plateau potentials and excitatory synaptic responses are prolonged in cultures pretreated with DNQX and AP5. A, Responses of CA1 cell distal dendrites to photorelease of caged glutamate with brief ( $4 \mathrm{~ms}$ ) and long ( $32 \mathrm{~ms})$ UV flashes in unlesioned control culture (left) and a culture pretreated with DNQX (40 $\mu \mathrm{M})$ and AP5 $(80 \mu \mathrm{m})$ for $7 \mathrm{~d}$ (right). $\boldsymbol{B}$, Plot of platea as a function chronic inactivity ( $n=6$ control and 7 treated dendrites). C, Responses of CA 1 cells to one stimulus or five stimuli at $50 \mathrm{~Hz}$ delivered for $7 \mathrm{~d}$ (black bars) were prolonged significantly (unpaired $t$ test; $n=7-33$ dendrites; ${ }^{*} p<0.05 ;{ }^{* *} p<0.01$ ) when elicited ttests). The prolongation of both types of response is comparable with that seen in deafferented CA1 cells (compare Figs. 1, 2). Error

Figure 6. SK2 mRNA and protein levels in area CA1 are not changed after deafferentation. $A$, Quantitative analysis of SK2 mRNA levels in area CA1 of cultures in which the Schaffer collateral pathway was lesioned $7 \mathrm{~d}$ earlier (black bar) or cultures incubated in $40 \mu \mathrm{m}$ DNQX and $80 \mu \mathrm{M}$ AP5 (gray bar), compared with control sister cultures (white bars). Mean SK2 expression is shown, normalized to the control gene for $18 \mathrm{~S}$ rRNA, from three replicates for each condition. $\boldsymbol{B}$, Western blot analysis of whole-brain homogenates from an SK2 knock-out mouse $(-/-)$ and a wild-type littermate $(+/+)$ (top), indicating that the antibody is specific for SK2. Actin immunoreactivity (bottom) indicates that comparable amounts of protein were loaded in each lane. C, Western blot analysis of SK2 protein (top) and actin (bottom) in area CA1 of control cultures, cultures treated with DNQX and AP5 for $7 \mathrm{~d}$, and cultures lesioned $7 \mathrm{~d}$ earlier. $D$, Mean SK2 protein levels, normalized to actin levels, were shown for the three replicates illustrated in C. Neither the expression of SK2 mRNA or the level of SK2 protein is affected by the two manipulations, suggesting that decreased dendritic SK2 function is mediated posttranslationally. Error bars indicate SEM. 


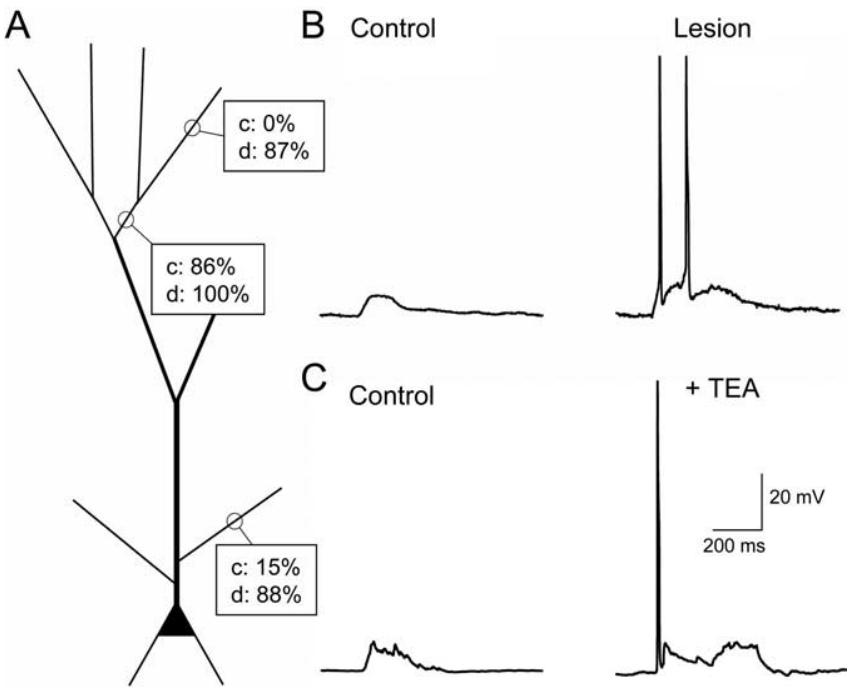

Figure 7. Enhanced glutamatergic triggering of action potentials with distal dendritic stimulation after deafferentation. $\boldsymbol{A}$, Percentage of cells in which photostimulation of different dendritic domains could elicit action potential discharge. Photostimulation of individual distal apical dendrites or terminal oblique dendrites was usually capable of eliciting action potentials in deafferented cells (d) but not control cells (c). Photostimulation at the base of the apical tuft, in contrast, was typically effective in both control and deafferented cells. The number of dendrites tested in each location ranged from 8 to 24 , as described in the last paragraph of Results. $\boldsymbol{B}$, Representative traces of responses to photolysis of caged glutamate in distal dendrites using identical stimulation parameters in a control and a deafferented cell. $V_{\mathrm{m}}=-70 \mathrm{mV}$. C, Representative traces of responses to photolysis of caged glutamate in distal dendrites of a control cell before and after application of $10 \mathrm{~mm}$ TEA. $V_{\mathrm{m}}=-65 \mathrm{mV}$. TEA thus mimics the effect of deafferentation in promoting the triggering of action potentials with distal dendritic stimulation.

phorylation by cAMP-dependent protein kinase may affect its targeting to the plasma membrane (Ren et al., 2006).

Our data do not permit a precise quantitative determination of the role of SK channel downregulation in the increased excitability after chronic inactivity. The prolongation of plateau potentials observed after acute block of SK channels in control cultures ranges from 1.9- to 2.9-fold, depending on the blocker used and the way in which the plateau potentials were evoked. This range is comparable with the prolongation of plateau potentials after deafferentation or DNQX/AP5 treatment (2.1- to 4.2-fold compared with plateau potentials in control cells). Although SK channel downregulation thus appears to be a major factor, a single pathophysiological mechanism is more often the exception than the rule in pathologic processes. Additional investigations should include an examination of deafferentation-induced changes in voltage-dependent $\mathrm{Ca}^{2+}$ channels, h-channel expression, and glutamate transporter function. Although the absence of a change in the decay time constants for either ph-EPSPs in response to weak photostimuli or single-stimulus synaptic EPSPs (Tables 1,2) suggest that glutamate clearance is not affected by deafferentation, it is possible that impaired glutamate clearance becomes apparent only when glutamate accumulation is high and transporters become saturated.

\section{Distal dendrites as a site of expression for reactive hyperexcitability}

Focal photorelease of glutamate onto dendritic domains of $<10$ $\mu \mathrm{m}$ has allowed us to localize the site of this intrinsic, reactive hyperexcitability. Plateau-like prolonged dendritic depolarization was readily triggered from, and mostly confined to, terminal dendritic compartments, providing evidence that the excitability of terminal dendrites can be specifically regulated in a homeostatic, but ultimately pathological, manner. Although the SK channel-mediated medium AHP was reduced, current injection at the soma failed to reveal any other significant differences between normally innervated and partially deafferented CA1 cells in action potential kinetics or threshold or in the frequencycurrent relationship of the cells. We have observed that dendritic stimulation was more likely to elicit fast action potentials after prolongation of plateau potentials with either SK channel blockers (Cai et al., 2004) or chronic deafferentation (Fig. 7). In normal pyramidal neurons, action potential initiation can occur in the dendrites, albeit at a higher threshold than at the soma and axon hillock (Golding and Spruston, 1998). The most straightforward explanation for the facilitation of action potential generation with direct dendritic stimulation after deafferentation is that prolongation of dendritic plateau potentials lowers the threshold for dendritic initiation of action potentials.

Neurons possess numerous plastic mechanisms that can compensate for changes in basal excitation. Neurons can upregulate the number and kinetics of their glutamate receptors. For example, when dissociated cultured neurons experience decreased glutamatergic excitation, the expression of NMDA and AMPA receptors can be upregulated (Furshpan and Potter, 1989; Williams et al., 1992; Turrigiano et al., 1998), but only if the cultures are at appropriate developmental age (Wierenga et al., 2006). Neurons can also modulate their intrinsic excitability. For example, when cultured cortical neurons are grown in TTX to eliminate sodium action potentials, the expression of sodium channels is upregulated, and the expression of potassium channels is downregulated (Desai et al., 1999). These previous studies were performed in young dissociated neuronal cultures, whereas the present experiments were performed in mature organotypic hippocampal slice cultures. Under these conditions, the dominant homeostatic reaction is a change in the intrinsic excitability of distal dendrites rather than a change in the expression of glutamate receptors.

There is evidence that the density of intrinsic conductances and glutamate receptors can be regulated independently at different dendritic locations (Hoffman et al., 1997; Andrasfalvy and Magee, 2001). The absence of changes in either the frequency or characteristics of action potentials elicited with depolarizing current injection at the soma suggests that the homeostatic response to deafferentation in our model is specifically confined to the distal dendritic branches that are the dominant site of afferent innervation (Bannister and Larkman, 1995). Interestingly, some antiepileptic drugs act by modulating intrinsic ion channels concentrated in dendrites (Poolos et al., 2002). Perhaps greater attention to compounds that specifically target dendritic channels may yield therapeutic agents that can more effectively treat hyperexcitable neurological disorders resulting from injury and deafferentation.

\section{Neural plasticity as a cause of disease}

Neural plasticity is generally viewed as an adaptive process that optimizes neuronal function. The prolongation of dendritic plateau potentials described here can be viewed as a logical homeostatic cellular response, serving to amplify diminished remaining excitatory inputs. However, compensation for decreased synaptic input with a progressively increased gain in intrinsic excitability leads to maladaptive hyperexcitability. Neuronal excitability apparently becomes "brittle" if there is sufficient deafferentation. That is, a point is reached at which a small perturbation in an input signal results in unstable output signals. Such maladaptive responses to deafferentation might contribute to several CNS 
diseases, including posttraumatic epilepsy, spasticity, and central pain syndrome. Like the aberrant dendritic responses described here, the manifestation of hyperexcitability in these conditions occurs well after the initial insult (Majkowski, 1990; Ramachandran, 2005). A better understanding of the mechanisms underlying deafferentation-induced plasticity may provide insights for the treatment and prevention of these reactive hyperexcitable conditions.

\section{References}

Andrasfalvy BK, Magee JC (2001) Distance-dependent increase in AMPA receptor number in the dendrites of adult hippocampal CA1 pyramidal neurons. J Neurosci 21:9151-9159.

Bannister NJ, Larkman A (1995) Dendritic morphology of CAl pyramidal neurones from the rat hippocampus: I. Branching patterns. J Comp Neurol 360:150-160.

Bildl W, Strassmaier T, Thurm H, Andersen J, Eble S, Oliver D, Knipper M, Mann M, Schulte U, Adelman JP, Fakler B (2004) Protein kinase CK2 is coassembled with small conductance $\mathrm{Ca}^{2+}$-activated $\mathrm{K}^{+}$channels and regulates channel gating. Neuron 43:847-858.

Bond CT, Herson PS, Strassmaier T, Hammond R, Stackman R, Maylie J, Adelman JP (2004) Small conductance $\mathrm{Ca}^{2+}$-activated $\mathrm{K}^{+}$channel knock-out mice reveal the identity of calcium-dependent afterhyperpolarization currents. J Neurosci 24:5301-5306.

Cai X, Liang CW, Muradlidharan S, Kao JPY, Tang C-M, Thompson SM (2004) Unique roles of SK and Kv4.2 potassium channels in dendritic integration. Neuron 44:351-364.

Chen K, Aradi I, Thon N, Eghbal-Ahmadi M, Baram TZ, Soltesz I (2001) Persistently modified h-channels after complex febrile seizures convert the seizure-induced enhancement of inhibition to hyperexcitability. Nat Med 7:331-337.

Desai NS, Rutherford LC, Turrigiano GG (1999) Plasticity in the intrinsic excitability of cortical pyramidal neurons. Nat Neurosci 2:515-520.

Fan Y, Fricker D, Brager DH, Chen X, Lu HC, Chitwood RA, Johnston D (2005) Activity-dependent decrease of excitability in rat hippocampal neurons through increases in $\mathrm{I}_{\mathrm{h}}$. Nat Neurosci 8:1542-1551.

Frick A, Johnston D (2005) Plasticity of dendritic excitability. J Neurobiol 64:100-115.

Frick A, Magee J, Johnston D (2004) LTP is accompanied by an enhanced local excitability of pyramidal neuron dendrites. Nat Neurosci 7:126-135.

Furshpan EJ, Potter DD (1989) Seizure-like activity and cellular damage in rat hippocampal neurons in cell culture. Neuron 3:199-207.

Gähwiler BH, Thompson SM, McKinney RA, Debanne D, Robertson RT (1998) Organotypic slice cultures of neural tissue. In: Culturing nerve cells, Ed 2 (Banker G, Goslin K, eds), pp 379-411. Cambridge, MA: MIT.

Galvan CD, Hrachovy RA, Smith KL, Swann JW (2000) Blockade of neuronal activity during hippocampal development produces a chronic focal epilepsy in the rat. J Neurosci 20:2904-2916.

Golding N, Spruston N (1998) Dendritic sodium spikes are variable triggers of axonal action potentials in hippocampal CA1 pyramidal neurons. Neuron 21:1189-1200

Hoffman DA, Magee JC, Colbert CM, Johnston D (1997) $\mathrm{K}^{+}$channel regulation of signal propagation in dendrites of hippocampal pyramidal neurons. Nature 387:869-875.

Jarsky T, Roxin A, Kath WL, Spruston N (2005) Conditional dendritic spike propagation following distal synaptic activation of hippocampal CA1 pyramidal neurons. Nat Neurosci 8:1667-1676.

Kao JPY (2006) Caged molecules: principles and practical considerations. In: Current protocols in neuroscience (Gerfen C, Holmes A, Rogawski M, Sibley D, Skolnick P, Wray S, eds) Unit 6.20. Hoboken, NJ: Wiley.

Li H, Prince DA (2002) Synaptic activity in chronically injured, epileptogenic sensory-motor neocortex. J Neurophysiol 88:2-12.

Lorincz A, Notomi T, Tamas G, Shigemoto R, Nusser Z (2002) Polarized and compartment-dependent distribution of HCN1 in pyramidal cell dendrites. Nat Neurosci 5:1185-1193.

Madison DV, Nicoll RA (1984) Control of the repetitive discharge of rat CA1 pyramidal neurones in vitro. J Physiol (Lond) 354:319-331.

Magee JC, Johnston D (2005) Plasticity of dendritic function. Curr Opin Neurobiol 15:334-342.

Majkowski J (1990) Posttraumatic epilepsy. In: Comprehensive epileptology (Mogens D, Lennart G, eds), 281-288. New York: Raven.
McKinney RA, Debanne D, Gähwiler BH, Thompson SM (1997) Lesioninduced axonal sprouting and hyperexcitability in the hippocampus in vitro: implications for the genesis of posttraumatic epilepsy. Nat Med 3:990-996.

McKinney RA, Capogna M, Dürr R, Gähwiler BH, Thompson SM (1999) Miniature synaptic events maintain dendritic spines via AMPA receptor activation. Nat Neurosci 2:44-49.

Ngo-Anh TJ, Bloodgood BL, Lin M, Sabatini BL, Maylie J, Adelman JP (2005) SK channels and NMDA receptors form a $\mathrm{Ca}^{2+}$-mediated feedback loop in dendritic spines. Nat Neurosci 8:642-649.

Nita DA, Cisse Y, Timofeev I, Steriade M (2006) Increased propensity to seizures after chronic cortical deafferentation in vivo. J Neurophysiol 95:902-913.

Poolos NP, Migliore M, Johnston D (2002) Pharmacological upregulation of h-channels reduces the excitability of pyramidal neuron dendrites. Nat Neurosci 5:767-774.

Prince DA (1978) Neurophysiology of epilepsy. Annu Rev Neurosci 1:395-415.

Prince DA, Tseng GF (1993) Epileptogenesis in chronically injured cortex: in vitro studies. J Neurophysiol 69:1276-1291.

Ramachandran VS (2005) Plasticity and functional recovery in neurology. Clin Med 5:368-373.

Ren Y, Barnwell LF, Alexander JC, Lubin FD, Adelman JP, Pfaffinger PJ, Schrader LA, Anderson AE (2006) Regulation of surface localization of the small conductance $\mathrm{Ca}^{2+}$-activated potassium channel, Sk2, through direct phosphorylation by cAMP-dependent protein kinase. J Biol Chem 281:11769-11779.

Sah P, Faber ES (2002) Channels underlying neuronal calcium-activated potassium currents. Prog Neurobiol 66:345-353.

Salin P, Tseng GF, Hoffman S, Parada I, Prince DA (1995) Axonal sprouting in layer $\mathrm{V}$ pyramidal neurons of chronically injured cerebral cortex. J Neurosci 15:8234-8245.

Shah MM, Anderson AE, Leung V, Lin X, Johnston D (2004) Seizureinduced plasticity of $\mathrm{h}$ channels in entorhinal cortical layer III pyramidal neurons. Neuron 44:495-508.

Sloviter RS (1991) Permanently altered hippocampal structure, excitability, and inhibition after experimental status epilepticus in the rat: the "dormant basket cell" hypothesis and its possible relevance to temporal lobe epilepsy. Hippocampus 1:41-66.

Smirnov S, Paalasmaa P, Uusisaari M, Voipio J, Kaila K (1999) Pharmacological isolation of the synaptic and nonsynaptic components of the GABA-mediated biphasic response in rat CA1 hippocampal pyramidal cells. J Neurosci 19:9252-9260.

Storm JF (1989) An after-hyperpolarization of medium duration in rat hippocampal pyramidal cells. J Physiol (Lond) 409:171-190.

Sutula T, Cascino G, Cavazos J, Parada I, Ramirez L (1989) Mossy fiber synaptic reorganization in the epileptic human temporal lobe. Ann Neurol 26:321-330.

Tang CM (2006) Photolysis of caged neurotransmitters: theory and procedures for light delivery. In: Current protocols in neuroscience (Gerfen C, Holmes A, Rogawski M, Sibley D, Skolnick P, Wray S, eds), Unit 6.21. Hoboken, NJ: Wiley.

Tauck DL, Nadler JV (1985) Evidence of functional mossy fiber sprouting in hippocampal formation of kainic acid-treated rats. J Neurosci 5:1016-1022.

Turrigiano GG (1999) Homeostatic plasticity in neuronal networks: the more things change, the more they stay the same. Trends Neurosci 22:221-227.

Turrigiano GG, Leslie KR, Desai NS, Rutherford LC, Nelson SB (1998) Activity-dependent scaling of quantal amplitude in neocortical neurons. Nature 391:892-896.

Wei DS, Mei YA, Bagal A, Kao JPY, Thompson SM, Tang C-M (2001) Compartmentalized and binary behavior of terminal dendrites in hippocampal pyramidal neurons. Science 293:2272-2275.

Wierenga CJ, Walsh MF, Turrigiano GG (2006) Temporal regulation of the expression locus of homeostatic plasticity. J Neurophysiol 96:2127-2133.

Williams K, Dichter MA, Molinoff PB (1992) Up-regulation of N-methylD-aspartate receptors on cultured cortical neurons after exposure to antagonists. Mol Pharmacol 42:147-151.

Yang L, Benardo LS (1997) Epileptogenesis following neocortical trauma from two sources of disinhibition. J Neurophysiol 78:2804-2810. 